\title{
Primary Small Cell Neuroendocrine Carcinoma of the Endometrium
}

\author{
Lisa N. Abaid ${ }^{a} \quad J o h n ~ S$. Cupp $^{b} \quad J o h n$ V. Brown III \\ Bram H. Goldstein ${ }^{\mathrm{a}}$ \\ ${ }^{a}$ Gynecologic Oncology Associates, and ${ }^{b}$ Department of Pathology, \\ Hoag Memorial Hospital Presbyterian, Newport Beach, Calif., USA
}

\section{Key Words}

Small cell neuroendocrine carcinoma $\cdot$ Endometrium - Gynecologic oncology

\begin{abstract}
Background: Small cell neuroendocrine carcinoma is very rarely encountered within the endometrium.

Case Study: A patient underwent a hysterectomy and salpingo-oophorectomy for a suspicious gynecologic condition. Pathology revealed invasive small cell neuroendocrine carcinoma of the endometrium; the neoplasm exhibited positive immunoreactivity for synaptophysin, pancytokeratin and CD56 but was negative for CD3 and CD20. Prior to chemotherapy, a completion lymphadenectomy was indicated to determine the presence of nodal metastases.
\end{abstract}

Conclusion: The prognosis of small cell neuroendocrine carcinoma of the endometrium is unfavorable but prompt detection with surgery and adjuvant therapy may confer a better clinical outcome.

\section{Introduction}

Small cell carcinomas are malignant neoplasms predominantly identified in the lungs [1]. These aggressive tumors can also arise in the female genital tract, albeit very rarely in the endometrium [2]. Hitherto, only 23 case studies involving stage I primary small cell neuroendocrine carcinoma of the endometrium have been documented in the literature $[2,3]$. The disease is a histologically distinct subtype of endometrial carcinoma with a propensity for metastatic infiltration and an unfavorable prognosis [4]. Patients are typically afflicted with this condition in their sixth decade of life [1, 2], often presenting with pelvic pain and hemorrhaging [5]; small cell carcinoma of the 
endometrium may also coincide with paraneoplastic disease and Cushing's syndrome $[6,7]$.

The diagnosis of primary small cell neuroendocrine carcinoma of the endometrium primarily relies upon immunohistochemical studies discerning neuroendocrine differentiation $[8,9]$. Histopathologically, the disease is characterized by small tumor cells exhibiting sheet-like growth of endometrial origin [8].

Despite reported clinical and pathologic data, only scant clinical data are available to elucidate this disease's behavior and optimal management $[1,2,4,8]$. We describe a very rare case involving a patient diagnosed with and treated for primary small cell neuroendocrine carcinoma of the endometrium.

\section{Case Report}

A 73-year-old, nulligravid woman was referred by her gynecologist in November 2011 for persistent postmenopausal spotting. An endometrial biopsy had been performed in October 2011 and showed only an atrophic endometrium. She had a recognized 5-cm uterine fibroid with documented stability since December 2007. Her medical history was significant for a breast biopsy in 1967, hypertension and pernicious anemia.

At the time of evaluation, her pelvic exam was consistent with a small fibroid and her cervix appeared normal. She had not had a Pap smear for 1 year, so a routine Pap was performed, which showed atypical cells suspicious for malignancy. Concern was raised for an endocervical carcinoma, and she subsequently underwent a loop electrosurgical excision procedure with endocervical and endometrial curettage. All specimens were negative for dysplasia and malignancy. Due to persistent spotting and the discrepancy between her Pap smear and biopsy findings, she was counseled to undergo hysterectomy for definitive diagnosis.

In January 2012, the patient underwent a robotic hysterectomy with bilateral salpingooophorectomy. During surgical exploration, a 12 -week size globular, fibroid uterus, normal tubes and ovaries, and a normal upper abdomen were encountered, with no visible evidence of malignancy. Frozen section results were benign and thus a lymphadenectomy was not performed.

Following final pathologic review, a stage IA, poorly differentiated small cell neuroendocrine carcinoma of the endometrium was identified (fig. 1a, b; fig. $2 \mathrm{a}-\mathrm{c}$ ) in addition to a 5-cm leiomyoma. Since the tumor (approx. $2 \mathrm{~cm}$ in largest dimension) was not visualized grossly due to an infiltrative rather than an exophytic appearance, the measurement was calculated in accordance with the tissue slides. There was evidence of lymph-vascular invasion and 75\% myometrial invasion; however, pelvic washing cytology was negative for invasive carcinoma. The neoplasm exhibited positive immunoreactivity for synaptophysin, pancytokeratin and CD56 but was negative for CD3 and CD20.

In January 2012, a PET/CT fusion of the chest, abdomen and pelvis was performed to determine if the disease was a primary or a metastatic lesion; no evidence of distant disease was found. Consequently, a comprehensive discussion regarding chemotherapy and a lymphadenectomy was initiated with the patient.

Since there was a significant concern regarding the neoplasm's aggressive histology and propensity for metastasis [4], the patient began 6 cycles of intravenous etoposide $\left(120 \mathrm{mg} / \mathrm{m}^{2}\right.$ days $1-3)$ and cisplatin $\left(60 \mathrm{mg} / \mathrm{m}^{2}\right)$ on day $1, \mathrm{q} 21$ days. In an attempt to determine the presence or absence of nodal metastases, the patient underwent a completion pelvic and para-aortic lymphadenectomy following the conclusion of cycle 2 ; lymph node sampling revealed inflammatory changes in the retroperitoneal space but no indication of a tumor in the abdomen. 


\section{Conclusion}

Small cell neuroendocrine carcinoma of the endometrium is an extremely rare and aggressive disease. Surgery and systemic, multi-modal therapy is warranted for the treatment of this neoplasm. In particular, laparoscopic management of women, even with early-stage small cell neuroendocrine carcinoma of the endometrium, appears to be a feasible option [2]. Active chemotherapy agents include etoposide and cisplatin [1, 9]; studies have also suggested that radiotherapy and hormonal therapy may enhance patient survival rate $[3,9]$. Regrettably, once a disease progression occurs, none of the aforementioned therapies have benefited patient outcomes [2].

In the current study, the patient's presentation was interesting insofar as the only concerning findings were persistent spotting and an atypical Pap smear. Despite two endometrial samplings, a visual inspection and a frozen section, the tumor was not initially identified. Consequently, the patient underwent a robotic hysterectomy with bilateral salpingo-oophorectomy upon which final pathology revealed a primary invasive small cell neuroendocrine carcinoma of the endometrium.

A negative PET/CT scan and planned chemotherapy notwithstanding, there was a significant concern for micrometastases $[1,10]$. Thus, a completion lymphadenectomy was indicated to assess disease status and determine optimal patient management.

Immunoreactivity studies are reportedly positive for CD56, chromogranin A, synaptophysin, p53 and p16 in small cell neuroendocrine carcinomas of the endometrium $[1,2,8]$. Immunohistochemical analysis may also be constructive in diagnosing and differentiating primary squamous cell carcinoma of the endometrium from benign and malignant diseases of the endometrium [3].The tumors in both the present case and a previously reported small cell neuroendocrine carcinoma study [2] were positive for synaptophysin; this protein is involved in synaptic transmission and frequently identified in neuroendocrine cells and the central nervous system.

The prognosis of small cell neuroendocrine carcinoma of the endometrium is usually unfavorable but prompt detection with surgery and adjuvant therapy may confer a better clinical outcome [11]. Despite the rare incidence of small cell neuroendocrine carcinoma of the endometrium, physicians should consider this outcome in patients who present with postmenopausal vaginal bleeding - even in the absence of a positive biopsy or ultrasound findings. 

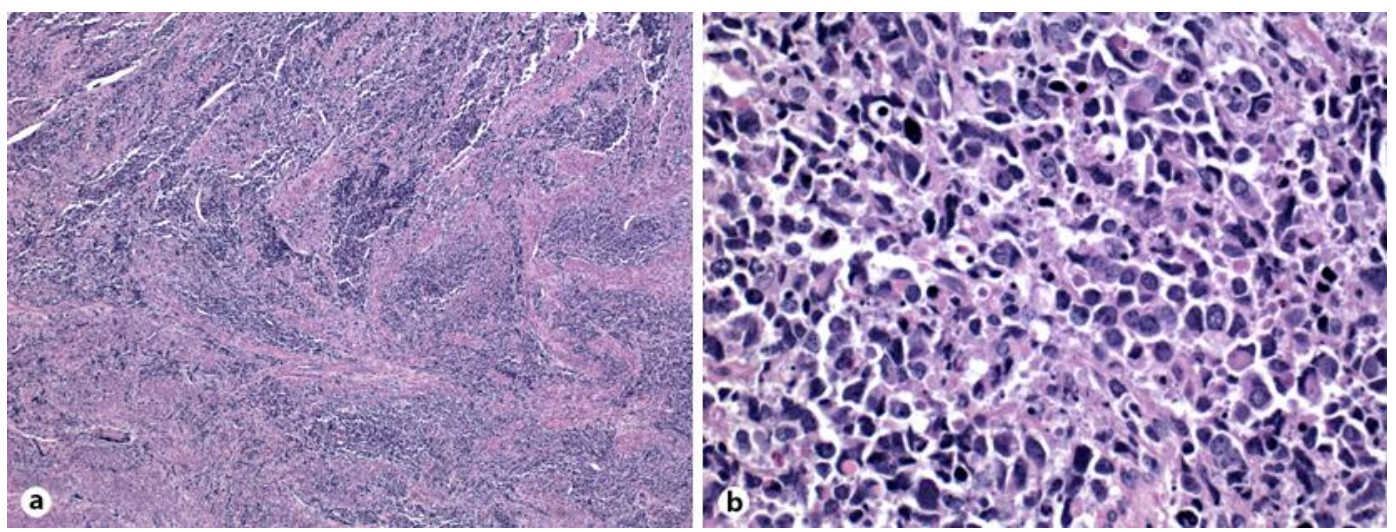

Fig. 1. a At low power (40× magnification), the tumor shows infiltration through the myometrial muscle (overall, endometrium and inner/outer myometrium involved). b At high power (400x magnification), the tumor cells are discohesive and pleomorphic and associated with abundant apoptotic debris; numerous mitotic figures are also identified.
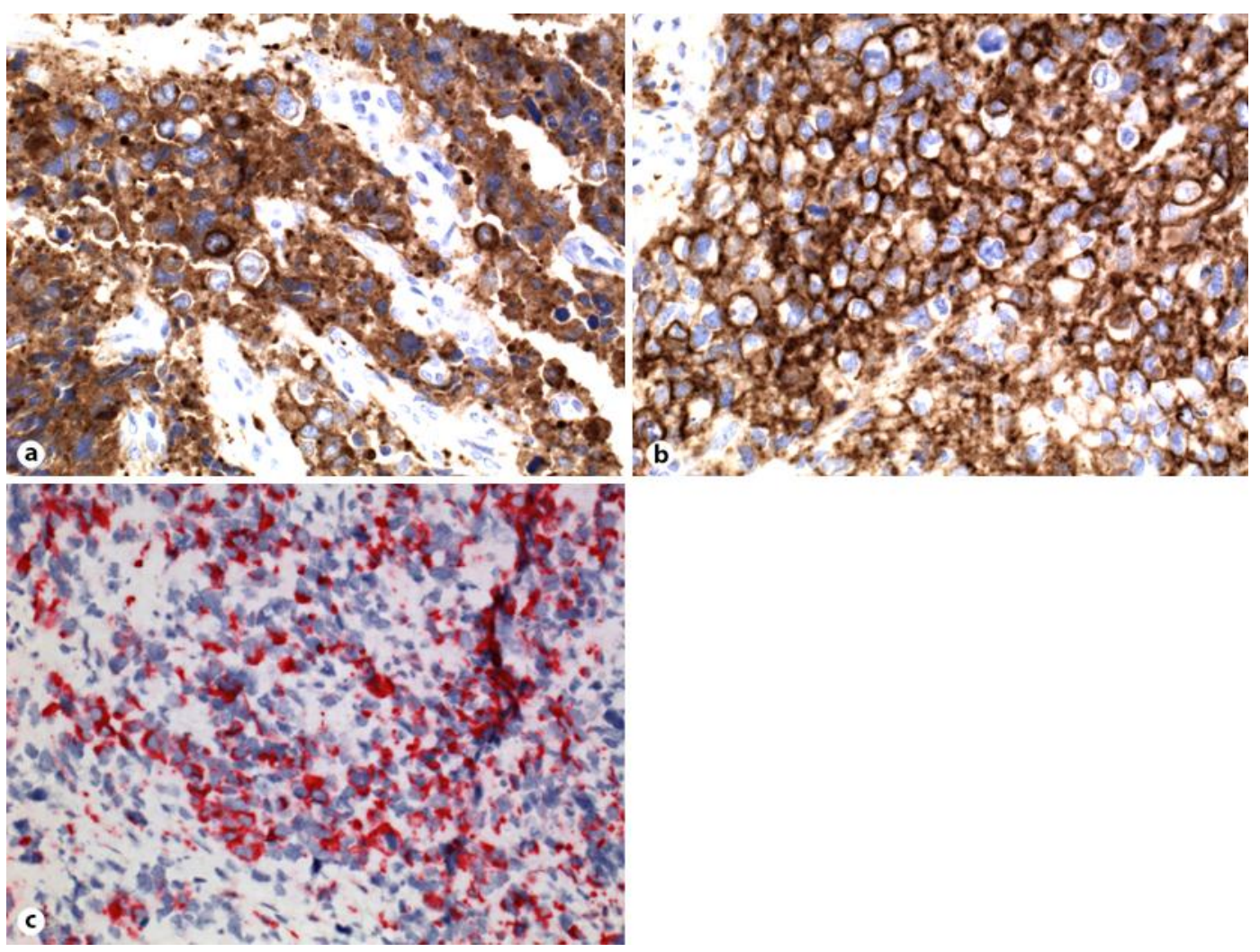

Fig. 2. a-c Immunostains exhibit diffuse positivity for two neuroendocrine markers, synaptophysin (400 $\times$ magnification) (a) and CD56 (400× magnification) (b), and variable positivity for pancytokeratin (400× magnification) (c). 


\section{References}

1 Kurtay G, Tașkin S, Kadan E, Sertçelik A: Primary endometrial small cell carcinoma. J Obstet Gynaecol 2012;32:104-106

-2 Bige O, Saatli B, Secil M, Koyuncuoglu M, Saygili U: Small cell neuroendocrine carcinoma of the endometrium and laparoscopic staging: a clinicopathologic study of a case and a brief review of the literature. Int J Gynecologic Cancer 2008;18:838-843.

-3 Hwang JH, Lee JK, Lee NW, Lee KW: Primary small cell carcinoma of the endometrium: report of a case with immunochemical studies. J Reprod Med 2010;55:81-86.

4 Huntsman DG, Clement PB, Gilks CB, Scully RE: Small-cell carcinoma of the endometrium. A clinicopathological study of sixteen cases. Am J Surg Pathol 1994;18:364-375.

-5 Meirmanov S, Nakashima M, Rogounovitch T, Fukuda E, Nakayama T, Sato F, Sekine I: Small cell carcinoma of the endometrium: report of a case with analysis of Wnt/beta-catenin pathway. Pathol Res Pract 2003;199:551-558.

-6 Meydanli MM, Erguvan R, Altinok MT, Altinok MT, Ataoglu 0, Kafkasli A: A. rare case of neuroendocrine small cell carcinoma of the endometrium with paraneoplastic membranous glomerulonephritis. Tumori 2003;89:213-217.

7 Sato H, Kanai G, Kajiwara H, Itoh J, Osamura RY: Small-cell carcinoma of the endometrium presenting as Cushing's syndrome. Endocr J 2010;57:31-38.

-8 Korcum AF, Aksu G, Ozdogan M, Erdogan G, Taskin O: Stage I small cell carcinoma of the endometrium: survival and management options. Acta Obstet Gynecol Scand 2008;87:122-126.

-9 González-Aragoneses F, Moreno-Mata N, Cebollero-Presmanes M, García-Yuste M, Cañizares-Carretero MA, Molins-López-Rodó L, Quevedo-Losada S, Torres-Lanzas J, Alvarez-Fernández E, Spanish Multicenter Study of Neuroendocrine Tumours of the Lung of the Spanish Society of Pneumonology ThoracicSurgery (EMETNE-SEPAR): Prognostic significance of synaptophysin in stage I of squamous carcinoma and adenocarcinoma of the lung. Cancer 2007;110:1776-1781.

10 Crowder S, Tuller E: Small cell carcinoma of the female genital tract. Semin Oncol 2007;34:57-63.

-11 Katahira A, Akahira J, Niikura H, Ito K, Moriya T, Matsuzawa S, Makinoda S, Oda t, Fujiwara K, Yaegashi $\mathrm{N}$ : Small cell carcinoma of the endometrium: report of three cases and literature review. Int J Gynecol Cancer 2004;14:1018-1023. 